\title{
Determinação da taxa de aplicação máxima anual de lodo de esgoto higienizado por processo alcalino em solos da região metropolitana de Curitiba
}

\section{Determination of maximum annual rate of application sewage sludge sanitized by alkaline process in soils of the metropolitan region of Curitiba, Brazil}

\author{
Lia Márcia K. de Souza Marin \\ Engenheira Agrônoma. Mestre em Geologia Ambiental pela Universidade Federal do Paraná (UFPR). Analista da Companhia de Saneamento do Paraná (Sanepar) \\ Simone Bittencourt \\ Engenheira Agrônoma. Mestre em Agronomia pela UFPR. Analista da Sanepar
}

Cleverson Vitorio Andreoli

Engenheiro Agrônomo. Doutor em Meio Ambiente e Desenvolvimento pela UFPR. Professor do Mestrado em Organizações e Desenvolvimento do Centro Universitário Franciscano do Paraná (UNIFAE). Gerente da Assessoria de Pesquisa e Desenvolvimento da Sanepar

\section{Cheila Carafini}

Engenheira Agrônoma. Estagiária da Sanepar

\begin{abstract}
Marcelo Ricardo de Lima
Engenheiro Agrônomo. Doutor em Agronomia pela UFPR. Professor do Departamento de Solos e Engenharia Agrícola da Universidade Federal do Paraná (UFPR)
\end{abstract}

\section{Beatriz Monte Serrat}

Engenheira Agrônoma. Doutora em Solos e Nutrição de Plantas pela Universidade de São Paulo (USP). Professora Colaboradora no Programa de Pós-graduação em Ciência do Solo da UFPR. Bolsista pelo Conselho Nacional de Desenvolvimento Científico e Tecnológico (CNPq), pela Financiadora de Estudos e Projetos (FINESP) e pela Sanepar

\section{Gil Alceu Mochida}

Engenheiro Civil. Assessor de Diretoria da Sanepar

\section{Resumo}

O objetivo deste estudo foi analisar as curvas de pH de três solos representativos da Região de Metropolitana de Curitiba para determinação das taxas de aplicação máxima anual de lodo de esgoto higienizado pelo processo de estabilização alcalina prolongada (lodo EAP), conforme estabelece a legislação, e para comparação com a metodologia de saturação por bases (V\%). Os solos foram incubados com seis doses de lodo EAP (pH 9,2) e o pH avaliado em 5 datas até 75 dias. O solo Cambissolo Húmico Distrófico típico, com a capacidade de troca de cátions e teor de carbono mais elevados, atingiu o pH 7 com 49 t ha ${ }^{-1}$ de sólidos totais (ST); o Latossolo Bruno Distrófico típico com 38 t ha ${ }^{-1}$ de ST, e o Cambissolo Háplico Distrófico típico, o mais restritivo, indicou que a aplicação anual de lodo EAP não deverá ultrapassar a 31 t ha-1 de ST. Sugeriu-se cautela na seleção do solo representativo. O método V\% recomendou quantidades de lodo EAP iguais ou ligeiramente superiores às que atingiram pH 6 pelo método de incubação.

Palavras-chave: Resolução CONAMA 375/06; incubação; biossólido; uso agrícola do lodo.

\begin{abstract}
The objective of this study was to analyze the $\mathrm{pH}$ curves of three representative soils of the Metropolitan Region of Curitiba for determining the maximum annual application rates of sewage sludge sanitized by prolonged alkaline stabilization process (EAP sludge), as stated in the legislation, and for comparison with the methodology of base saturation (V\%). The soils were incubated with six doses of sludge EAP (pH 9.2) and pH measured on 5 dates, up to 75 days. The Inceptisol from Piraquara with the cation exchange capacity and higher carbon content reached the $\mathrm{pH} 7$ with $49 \mathrm{t}$ ha- ${ }^{-1}$ of total solids (ST); the Oxisol with $38 \mathrm{t}$ ha- ${ }^{-1}$ of ST, and to Inceptisol from Pinhais, the most restrictive, indicated that the annual application of sludge EAP shall not exceed the $31 \mathrm{t}$ ha ${ }^{-1}$ of ST. Caution in selecting representative soil was suggested. The method V\% recommended EAP sludge quantities equal or slightly higher than that reached pH 6 by the method of incubation.
\end{abstract}

Keywords: Resolution CONAMA 375/2006; incubation; biosolids; agricultural use of sewage sludge.

Endereço para correspondência: Simone Bittencourt - Companhia de Saneamento do Paraná - Rua Engenheiro Rebouças, 1376 - $80215-900$ - Curitiba (PR), Brasil e-mail: sbittencourt@sanepar.com.br

Recebido: 27/7/09 - Aceito: 30/7/10 - Reg. ABES: 021/09 


\section{Introdução}

No Brasil, a reciclagem agrícola do lodo de esgoto segue as determinações da resolução do Conselho Nacional do Meio Ambiente (CONAMA) 375/06 (BRASIL, 2006) e, no Estado do Paraná, essa é complementada pela resolução da Secretaria do Estado do Meio Ambiente (SEMA) 021/09 (PARANÁ, 2009). Tais resoluções estabelecem critérios para a determinação da taxa de aplicação máxima anual de lodo de esgoto, entre eles o de $\mathrm{pH}$, de modo a garantir que o $\mathrm{pH}$ final da mistura solo-lodo de esgoto não ultrapasse o limite de 7,0.

O lodo de esgoto gerado nas estações de tratamento de esgoto (ETEs) da Sanepar é higienizado pelo processo de estabilização alcalina prolongada (lodo EAP) (PARANÁ, 2009). Dados da Sanepar (2007) apresentam para as ETEs da Região Metropolitana de Curitiba uma produção estimada de $5.076 \mathrm{t} \mathrm{ano}^{-1}$ de sólidos totais (ST) de lodo de esgoto. O processo é sanitariamente eficiente (EPA, 1992; FERNANDES et al, 1996; THOMAZ-SOCCOL; PAULINO; CASTRO, 1999), e ainda converte o lodo em corretivo de acidez do solo, o que pode trazer vantagens agrícolas e econômicas aos agricultores.

A correção da acidez dos solos é considerada uma prática fundamental para o uso eficiente dos fertilizantes pelas plantas, especialmente para as culturas sensíveis aos fatores de acidez do solo (COMISSÃO DE QUÍMICA E FERTILIDADE DO SOLO, 1989). A faixa de pH em água entre 6,0 e 6,5 tem sido considerada excelente para a maioria das plantas cultivadas, todavia algumas culturas (milho, trigo e soja) apresentaram efeito depressivo na produtividade quando esses valores foram superiores a 7,0 (MELLO et al, 1984), como no caso da aplicação excessiva de lodo EAP realizada por Chueiri et al (2007) na cultura do trigo.

Diante do exposto, o objetivo do presente estudo foi obter e analisar curvas de elevação de pH de três solos da Região Metropolitana de Curitiba para determinação da taxa de aplicação máxima anual de lodo EAP, em função do critério de elevação de $\mathrm{pH}$, conforme estabelece a legislação vigente, e para comparação com o método de saturação por bases.

\section{Material e métodos}

Três tipos de solos de importância agrícola foram selecionados e coletados na Região Metropolitana de Curitiba (PR): Cambissolo Háplico Distrófico típico (CXd) (LIMA, 2005) no município de Pinhais (coordenadas UTM 7190513 N 688198 E e altitude de 930 m); Cambissolo Húmico Distrófico típico (CHd) (SANTOS JÚNIOR; LIMA; BICCA NETO, 2005) no município de Piraquara (coordenadas UTM 7186767 N 696819 E e altitude de 935 m); Latossolo Bruno Distrófico típico (LBd) (Fasolo et al, 2002) no município de Araucária (coordenadas UTM 7162329 N 653008 E e altitude de 847 m), cujas características são apresentadas na Tabela 1. O clima da região, segundo a classificação de Köppen, é do tipo Cfb (CAVIGLIONE et al, 2000).

Em maio de 2007, o experimento foi conduzido em laboratório, empregando-se o ensaio de incubação (BRASIL, 2006). A unidade experimental constou de $200 \mathrm{~g}$ de solo seco $\left(55^{\circ} \mathrm{C}\right)$, em potes plásticos de 1 dm$^{3}$ (diâmetro de $18 \mathrm{~cm}$ ) com tampa perfurada.

Utilizou-se o lodo de esgoto da ETE Belém, resultante de tratamento aeróbio, desaguado por prensas e centrífuga e higienizado pelo processo de EAP (Tabela 2), adicionando-se cal na proporção de 50\% de sólidos totais.

O delineamento experimental utilizado foi o inteiramente casualizado com três repetições, em arranjo fatorial 6×3×6 (MONTGOMERY, 2001), sendo seis doses do fator lodo EAP: 0, 5, 10, 20, 40 e $80 \mathrm{t} \mathrm{ha}^{-1}$ de ST, três tipos de solo (CXd, CHd e LBd), num total de 54 potes e 6 períodos: 7, 14, 30, 45, 60 e aos 75 dias de incubação, quando foram retiradas amostras de aproximadamente $25 \mathrm{~g}$ de solo de cada pote.

Tabela 1 - Atributos químicos e físicos iniciais dos solos selecionados

\begin{tabular}{|c|c|c|c|c|c|c|c|c|c|c|c|c|c|c|c|c|}
\hline \multirow{2}{*}{ Solo } & \multicolumn{2}{|c|}{$\mathrm{pH}$} & \multirow[t]{2}{*}{$\mathrm{Al}^{+3}$} & \multirow{2}{*}{$\mathrm{H}^{+}+\mathrm{Al}^{+0}$} & $\mathrm{Ca}^{+2}$ & $\mathrm{Mg}^{+2}$ & $\mathrm{~K}^{+}$ & \multirow[t]{2}{*}{$\mathrm{T}$} & \multirow{2}{*}{$\begin{array}{c}P \\
\mathrm{mg} \mathrm{dm^{-3 }}\end{array}$} & \multirow{2}{*}{$\begin{array}{c}\text { C } \\
\mathrm{g} \mathrm{dm}^{-3}\end{array}$} & \multirow{2}{*}{$\begin{array}{l}\mathrm{V} \\
\%\end{array}$} & Areia & Silte & Argila & Ds & U \\
\hline & $\mathrm{CaCl}_{2}$ & SMP & & & & \multicolumn{2}{|c|}{ 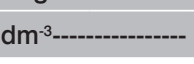 } & & & & & \multicolumn{3}{|c|}{ 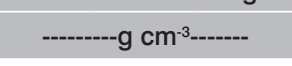 } & $\mathrm{g} \mathrm{dm}^{-3}$ & $\mathrm{~g} \mathrm{~kg}^{-1}$ \\
\hline CXd & 4,4 & 5,3 & 0,9 & 8,4 & 2 & 0,8 & 0,11 & 11,31 & 2,3 & 27,5 & 26 & 185 & 290 & 525 & 1,18 & 415 \\
\hline $\mathrm{CHd}$ & 4,1 & 4,5 & 3,8 & 15,2 & 0,5 & 0,4 & 0,15 & 16,25 & 1,9 & 45,6 & 6 & 330 & 245 & 425 & 0,69 & 467,6 \\
\hline LBd & 4 & 4,8 & 2,6 & 12,1 & 0,4 & 0,3 & 0,22 & 13,02 & 2,5 & 26,9 & 7 & 117 & 233 & 650 & 0,87 & 485,1 \\
\hline
\end{tabular}

*Análises químicas realizadas pelo laboratório de Fertilidade do Solo da Universidade Federal do Paraná (UFPR) (MARQUES; MOTTA, 2003); Análises físicas realizadas pelo laboratório de Física do Solo da UFPR (EMBRAPA, 1997) (profundidade de coleta 0-20 cm); T: Capacidade de troca de cátions; C: carbono orgânico; V: saturação por bases; Ds: densidade do solo; U: umidade do solo na capacidade de campo (0,033 Mpa); CXd: Cambissolo Háplico Distrófico típico; CHd: Cambissolo Húmico Distrófico típico; LBd: Latossolo Bruno Distrófico típico.

Tabela 2 - Caracterização do lodo EAP produzido na estação de tratamento de esgoto - Belém*

$\begin{array}{cccccccc}\mathrm{Ca}(\mathrm{CaO}) & 345 \mathrm{~g} \mathrm{~kg}^{-1} & \mathrm{~N} \text { total } & 11,1 \mathrm{~g} \mathrm{~kg}^{-1} & \text { Cinzas } & 619,1 \mathrm{~g} \mathrm{~kg}^{-1} & \text { Cromo total } & 50,9 \mathrm{mg} \mathrm{kg}^{-1} \\ \mathrm{P}\left(\mathrm{P}_{2} \mathrm{O}_{5}\right) & 6,3 \mathrm{~g} \mathrm{~kg}^{-1} & \text { Matéria orgânica } & 277 \mathrm{~g} \mathrm{~kg}^{-1} & \text { Cádmio } & <0,2 \mathrm{mg} \mathrm{kg}^{-1} & \text { Mercúrio } & 0,10 \mathrm{mg} \mathrm{kg}^{-1} \\ \mathrm{Mg}(\mathrm{MgO}) & 17,2 \mathrm{~g} \mathrm{~kg}^{-1} & \text { Sólidos totais } & 581 \mathrm{~g} \mathrm{~kg}^{-1} & \text { Chumbo } & 14,7 \mathrm{mg} \mathrm{kg}^{-1} & \text { Níquel } & 26,8 \mathrm{mg} \mathrm{kg}^{-1} \\ \mathrm{~K}\left(\mathrm{~K}_{2} \mathrm{O}\right) & 3,7 \mathrm{~g} \mathrm{~kg}^{-1} & \text { Umidade }\left(105^{\circ} \mathrm{C}\right) & 419 \mathrm{~g} \mathrm{~kg}^{-1} & \text { Cobre } & 124 \mathrm{mg} \mathrm{kg}^{-1} & \text { Zinco } & 323 \mathrm{mg} \mathrm{kg}^{-1} \\ \mathrm{pH}(11 / 06) & 12,2 & \mathrm{pH}(09 / 07)^{\star \star} & 9,2 & & & & \end{array}$

*Análises do lote B41, realizadas pelo Bioagri Ambiental, 30 dias após a higienização; ** Análise para o início do experimento.

Lodo EAP: lodo de esgoto higienizado pelo método de estabilização alcalina prolongada (PARANÁ, 2009). 
O solo foi mantido incubado na umidade à capacidade de campo (0,033 MPa) (Tabela 1$)$, em local coberto, em temperatura ambiente, sendo a umidade verificada a cada sete dias. $\mathrm{O} \mathrm{pH}$ em $\mathrm{CaCl}_{2}$ $0,01 \mathrm{~mol} \mathrm{dm}^{-3}$ (relação solo: solução 1:2,5) foi determinado conforme a metodologia da Empresa Brasileira de Pesquisa Agropecuária (1997) nos solos amostrados a cada período de avaliação. Aos 125 dias de incubação foi realizada a análise química da mistura solo/ lodo (MARQUES; MOTTA, 2003) para verificar a continuidade das reações e, devido ao reduzido material remanescente, agruparam-se as repetições por tratamento.

A variável dependente $\left(\mathrm{pH}\right.$ em $\left.\mathrm{CaCl}_{2}\right)$ foi analisada por meio do modelo linear generalizado, com dois fatores categóricos (período de avaliação e tipos de solos) e um fator quantitativo (lodo) (DEMETRIO, 2001). As médias foram comparadas por meio do teste de Tukey, ao nível de 95\% de confiabilidade (BARBIN, 2004).

Para interação entre solo e lodo foi obtida a curva de elevação do pH em função das doses de lodo adicionadas, para cada solo, visando identificar a taxa de aplicação máxima anual. A análise de regressão polinomial do $\mathrm{pH}$ versus dose de lodo EAP foi realizada considerando-se o limite superior do intervalo de predição com 95\% de confiabilidade (DRAPER; SMITH, 1998; R DEVELOPMENT, 2008), para indicar a quantidade de lodo EAP que não ultrapassasse o pH 7,0. Dessa forma, aumenta-se a segurança em relação ao uso direto da equação. Enquanto a equação representa a média das ocorrências e pode resultar em valores futuros tanto inferiores quanto superiores ao $\mathrm{pH} 7,0$, o limite superior do intervalo de predição, com 95\% de confiabilidade, melhor atende a legislação, porquanto aumenta a probabilidade de não se ultrapassar o pH 7,0 em solos que recebam a quantidade de lodo EAP recomendada por esse limite.

O método de incubação foi comparado ao método de saturação por bases (V\%), conforme descrito por Andreoli, Pegorini e Fernandes (2001), visando avaliar o potencial de utilização dos valores obtidos em análise de rotina dos atributos químicos e físicos de cada um dos solos estudados.

\section{Resultados e discussão}

\section{Atributos dos solos}

Observa-se, na Tabela 3, que a elevação das doses provocou aumentos dos teores de fósforo, cálcio e magnésio, refletindo a composição do lodo EAP nos três (Tabela 2).

Para os valores de $\mathrm{pH}$, o CXd partiu de uma acidez classificada por Olenik et al (2004) como alta, enquanto os demais solos (Tabela 1) de uma acidez muito alta $(\mathrm{pH}<4,3)$, resultando em valores diferenciados para cada solo aos 125 dias de incubação com lodo EAP, conforme Tabela 3. Verifica-se que o solo CHd, com teor de carbono 40\% maior que os demais, apresentou-se mais resistente à neutralização do alumínio trocável e à elevação do pH, apresentando nível de alumínio fitotóxico na dose de $10 \mathrm{t} \mathrm{ha}^{-1}$ de ST (superior a 0,5 $\mathrm{cmol} \mathrm{dm}^{-3}$ conforme Mello et al, 1984 e Raij et al, 1996) e ainda mantendo pH inferior a 6 mesmo na dose $40 \mathrm{t} \mathrm{ha}^{-1}$ de ST de lodo EAP.

Os valores de $\mathrm{pH}$ do solo entre 6 a 6,5 são adequados para o desenvolvimento da maioria das plantas cultivadas, no entanto deve-se ter cautela para não se ultrapassar níveis recomendados de $\mathrm{pH}$ evitando-se desequilíbrios com efeitos depressivos sobre a produtividade de algumas culturas (MELLO et al, 1984; FAGÉRIA, 2001). Isto deverá ser observado em casos como dos solos CXd e LBd, os quais, na dose $40 \mathrm{t} \mathrm{ha}{ }^{-1}$ ST de lodo EAP, já apresentaram valores de pH próximos a 7. Essas variações entre os solos sugerem que esses estudos sejam realizados com maior número e diversidade de solos de várias regiões para auxiliar na discussão sobre a seleção do "solo predominante", o qual é referido na seção VII, art. 17, item II da resolução CONAMA 375/06 (BRASIL, 2006).

Tabela 3 - Atributos químicos de solos da Região Metropolitana de Curitiba, aos 125 dias de incubação com lodo EAP (dados sem repetição)

\begin{tabular}{|c|c|c|c|c|c|c|c|c|c|c|c|}
\hline \multirow{2}{*}{ Solo } & Tratamento & $\mathrm{pH}$ & $\mathrm{Al}^{+3}$ & $\mathrm{H}^{+}+\mathrm{Al}^{+3}$ & $\mathrm{Ca}^{+2}$ & $\mathrm{Mg}^{+2}$ & $\mathrm{~K}^{+}$ & $\mathrm{T}$ & $\mathrm{P}$ & C & V \\
\hline & $\left(\mathrm{t} \mathrm{ha}{ }^{-1}\right.$ de ST) & $\mathrm{CaCl}_{2}$ & \multicolumn{6}{|c|}{ - } & $\mathrm{mg} \mathrm{dm}{ }^{-3}$ & $\mathrm{~g} \mathrm{dm}^{-3}$ & $\%$ \\
\hline \multirow[t]{5}{*}{ CXd } & 5 & 4,7 & 0,4 & 6,7 & 5,2 & 2 & 0,16 & 14,06 & 2 & 28,1 & 52 \\
\hline & 10 & 5,1 & 0 & 5,4 & 6 & 2,6 & 0,16 & 14,16 & 3,2 & 29,3 & 62 \\
\hline & 20 & 5,9 & 0 & 3,7 & 7 & 3,2 & 0,15 & 14,05 & 5,7 & 31,7 & 74 \\
\hline & 40 & 6,9 & 0 & 2 & 8 & 3,8 & 0,15 & 13,95 & 13 & 29,3 & 86 \\
\hline & 80 & 7,6 & 0 & 1,5 & 8,7 & 4,8 & 0,15 & 15,15 & 30,8 & 28,1 & 90 \\
\hline \multirow[t]{5}{*}{$\mathrm{CHd}$} & 5 & 4,4 & 2,6 & 14,4 & 3 & 1,8 & 0,18 & 19,38 & 6,8 & 53,4 & 26 \\
\hline & 10 & 4,6 & 1,5 & 12,1 & 3,3 & 2 & 0,17 & 17,57 & 6 & 57 & 31 \\
\hline & 20 & 5,1 & 0 & 8,4 & 6 & 4,1 & 0,16 & 18,66 & 10,8 & 48,6 & 55 \\
\hline & 40 & 5,9 & 0 & 4,6 & 8,7 & 6,4 & 0,17 & 19,87 & 13,7 & 53,4 & 77 \\
\hline & 80 & 7,2 & 0 & 2 & 10,1 & 6,7 & 0,17 & 18,97 & 23,1 & 51 & 89 \\
\hline \multirow[t]{5}{*}{ LBd } & 5 & 4,3 & 1,2 & 10,5 & 2,4 & 1,5 & 0,23 & 14,63 & 3 & 30,5 & 28 \\
\hline & 10 & 4,7 & 0,4 & 8,4 & 3,5 & 2,3 & 0,23 & 14,43 & 3,7 & 34,1 & 42 \\
\hline & 20 & 5,4 & 0 & 5,4 & 5,2 & 3,4 & 0,21 & 14,21 & 4,8 & 34,1 & 62 \\
\hline & 40 & 6,8 & 0 & 2,4 & 6,7 & 4 & 0,19 & 13,29 & 9,8 & 36,5 & 82 \\
\hline & 80 & 7,6 & 0 & 1,5 & 7,8 & 5 & 0,2 & 14,5 & 19,1 & 29,9 & 90 \\
\hline
\end{tabular}

Lodo EAP: lodo de esgoto higienizado pelo método de estabilização alcalina prolongada (PARANÁ, 2009). Metodologia de análise segundo Marques e Motta (2003); SB: Soma de bases; T: capacidade de troca de cátions; C: carbono orgânico; V: saturação por bases; CXd: Cambissolo Háplicco Distrófico típico; CHd: Cambissolo Húmico Distrófico típico; LBd: Latossolo Bruno Distrófico típico. 
Tabela 4 - Valores $\mathrm{pH}\left(\mathrm{CaCl}_{2}\right)$ dos solos, nas diferentes doses de lodo EAP

\begin{tabular}{|c|c|c|c|c|c|c|c|c|c|c|c|c|c|c|c|c|c|c|c|}
\hline \multirow{3}{*}{ SOLO } & \multirow{3}{*}{$\begin{array}{c}\mathrm{N}^{\circ} \text { de } \\
\text { amostras }\end{array}$} & \multicolumn{18}{|c|}{ Dose de lodo de esgoto higienizado (t. ha-1) } \\
\hline & & \multicolumn{3}{|c|}{0} & \multicolumn{3}{|c|}{5} & \multicolumn{3}{|c|}{10} & \multicolumn{3}{|c|}{20} & \multicolumn{3}{|c|}{40} & \multicolumn{3}{|c|}{80} \\
\hline & & \multicolumn{2}{|c|}{$\mathrm{pH}$} & CV \% & \multicolumn{2}{|c|}{$\mathrm{pH}$} & \multirow{2}{*}{$\begin{array}{c}\text { CV \% } \\
1,9\end{array}$} & \multicolumn{2}{|c|}{$\mathrm{pH}$} & \multirow{2}{*}{$\begin{array}{c}\text { CV \% } \\
2,9\end{array}$} & \multicolumn{2}{|c|}{$\mathrm{pH}$} & \multirow{2}{*}{$\begin{array}{c}\text { CV \% } \\
4,9\end{array}$} & \multicolumn{2}{|c|}{$\mathrm{pH}$} & \multirow{2}{*}{$\begin{array}{c}\text { CV \% } \\
2\end{array}$} & \multicolumn{2}{|c|}{$\mathrm{pH}$} & $\mathrm{CV} \%$ \\
\hline CXd & 18 & 4,8 & A & 2 & 5,1 & A & & 5,5 & A & & 6,2 & A & & 7 & A & & 7,5 & A & 1,5 \\
\hline $\mathrm{CHd}$ & 18 & 4,3 & B & 2 & 4,6 & B & 2,7 & 4,9 & B & 4 & 5,6 & B & 2,1 & 6,3 & $\mathrm{C}$ & 4 & 7,3 & A & 2,8 \\
\hline LBd & 18 & 4,2 & $C$ & 2,9 & 4,5 & C & 3,5 & 4,9 & B & 4,8 & 5,5 & B & 6,8 & 6,5 & B & 5,4 & 7,4 & A & 5,2 \\
\hline Geral & 54 & 4,4 & & 6,5 & 4,8 & & 5,9 & 5,1 & & 6,7 & 5,7 & & 7,2 & 6,6 & & 5,9 & 7,4 & & 3,6 \\
\hline
\end{tabular}

Médias com letras iguais na coluna não diferem estatisticamente pelo teste de Tukey ao nível de $5 \%$ significância.

Lodo EAP: lodo de esgoto higienizado pelo método de estabilização alcalina prolongada (PARANÁ, 2009); CXd: Cambissolo Háplicco Distrófico típico; CHd: Cambissolo Húmico Distrófico típico; LBd: Latossolo Bruno Distrófico típico.

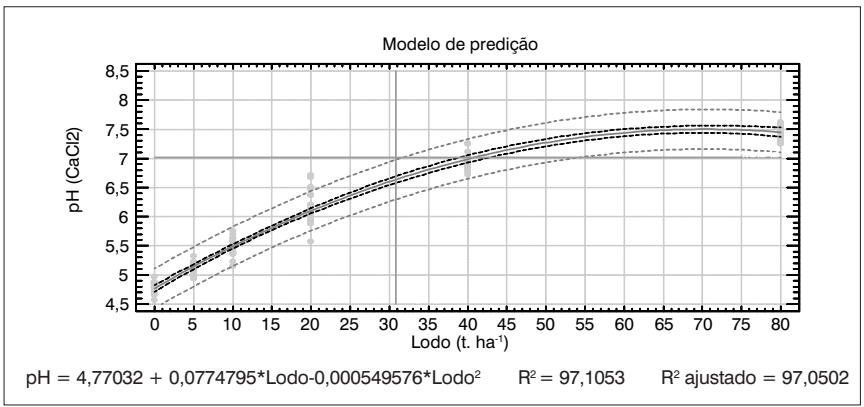

Figura 1 - Regressão (polinomial de $2^{\mathrm{a}}$ ordem) do solo cambissolo háplico distrófico típico com intervalo de confiança da média dos valores de pH observados (IC95\% - linha preta), intervalo de predição dos valores de $\mathrm{pH}$ preditos (IP95\% - linha cinza) e limite superior (IP95\% para pH 7 = 31 t. ha-1 ST de lodo EAP)

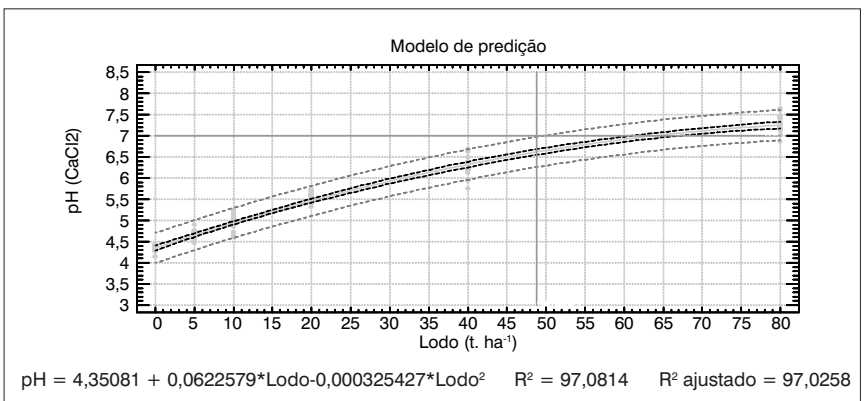

Figura 2 - Regressão (polinomial de $2^{\mathrm{a}}$ ordem) do solo cambissolo húmico distrófico típico com intervalo de confiança da média dos valores de pH observados (IC95\% - linha preta), intervalo de predição dos valores de $\mathrm{pH}$ preditos (IP95\% - linha cinza) e limite superior (IP95\% para pH $7=$ 49 t. ha-1 ST de lodo EAP)

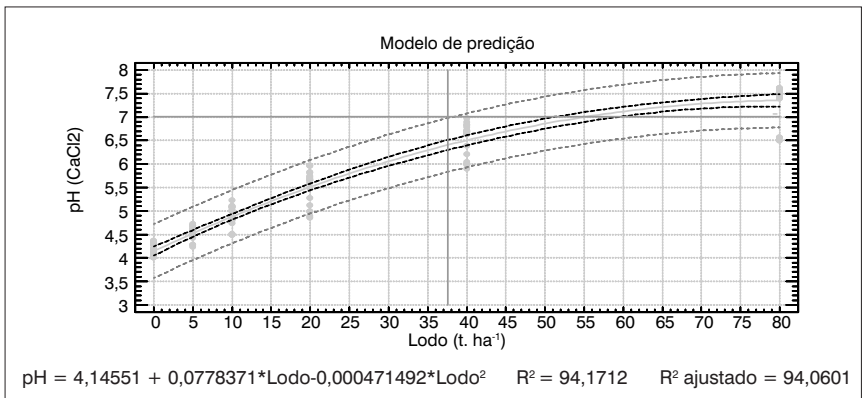

Figura 3 - Regressão (polinomial de $2^{\text {a }}$ ordem) do solo latossolo bruno distrófico típico com intervalo de confiança da média dos valores de $\mathrm{pH}$ observados (IC95\% - linha preta), intervalo de predição dos valores de pH preditos ( $\mathrm{IP}_{95 \%}$ - linha cinza) e limite superior (IP95\% para pH $7=38$ t. ha-1 ST de lodo EAP)

\section{Análise do experimento}

$\mathrm{Na}$ análise geral dos resultados do experimento de incubação, a variável pH apresenta-se estatisticamente homogênea, não sendo observado nos resultados da análise da variância o efeito do período de incubação e nem a interação deste com os outros fatores analisados, o que provavelmente está vinculado ao fato de as medidas terem iniciado no sétimo dia após a aplicação do lodo EAP, período de menor intensidade das reações de alcalinização (RAIJ, 1991).

O efeito da dose de lodo EAP aplicada apresentou interação com tipo de solo estudado. A Tabela 4 compara as médias dos valores de $\mathrm{pH}$ entre os solos selecionados para cada dose de lodo EAP, considerando a média do período de incubação. Observa-se no tratamento sem lodo EAP a superioridade do solo CXd, a qual se repete até a dose de 40 t ha-1 ${ }^{-1}$ confirmando a maior resistência dos solos CHd e LBd à elevação do pH.

\section{Curvas de pH em função da dose de lodo EAP}

Verifica-se nas Figuras 1, 2 e 3, por meio das equações das curvas de pH em função das doses de lodo EAP aplicadas que os três solos apresentaram elevação de $\mathrm{pH}$ após a adição do lodo, como resultado da capacidade alcalinizante do produto (Tabela 2), semelhante ao observado sob condições de campo por SILVA et al (2001), BARCELAR et al (2001) e MATOS, FIA e AGUIRRE (2005).

Utilizando-se o limite superior do limite de predição (95\% de confiabilidade) das equações apresentadas nas Figuras 1, 2 e 3, verificou-se que entre os três solos estudados o solo CHd obteve a maior taxa de aplicação máxima anual de lodo EAP, $49 \mathrm{t} \mathrm{ha}^{-1}$ ST (Figura 2). O solo LBd apresentou-se com resposta intermediária, com taxa de aplicação máxima anual de $38 \mathrm{t} \mathrm{ha{ } ^ { - 1 }}$ ST (Figura 3).

O solo CXd foi o que apresentou maior restrição para uso de lodo EAP, pois atingiu o pH 7 com a menor quantidade, $31 \mathrm{t} \mathrm{ha} \mathrm{h}^{-1} \mathrm{ST}$ (Figura 1). Devido ao fato deste solo apresentar-se com pH superior aos demais no início da incubação e a seus demais atributos, já comentados, entre eles os menores valores iniciais de alumínio trocável, acidez potencial e capacidade de troca catiônica (Tabela 2), este necessitou de menor quantidade de lodo EAP para atingir o pH 7. Dessa forma, o solo CXd define, entre os três solos estudados, o valor máximo da taxa de aplicação máxima anual de lodo EAP. 
Tabela 5 - Comparação de métodos de recomendação de quantidade de lodo EAP

\begin{tabular}{|c|c|c|c|c|}
\hline \multirow{4}{*}{ Solo } & \multicolumn{4}{|c|}{ Métodos de recomendação para a correção do solo } \\
\hline & \multicolumn{2}{|c|}{$\begin{array}{l}\text { Saturação por Bases } \\
\text { Andreoli, Pegorinie e Fernandes (2001) }\end{array}$} & \multicolumn{2}{|c|}{ Curva de incubação* } \\
\hline & $\begin{array}{c}\text { (PRNT da cal } 120 \% ; \mathrm{V}_{2} \\
=70 \%)\end{array}$ & $\mathrm{pHCaCl}_{2} 6,0$ & $\mathrm{pHCaCl}_{2} 6,5$ & $\mathrm{pHCaCl}_{2} 7,0^{\star *}$ \\
\hline & \multicolumn{4}{|c|}{ Quantidade de lodo EAP ( $t$ ha $^{-1} \mathrm{ST}$ ) } \\
\hline CXd & 12,4 & 12 & 21 & 31 \\
\hline $\mathrm{CHd}$ & 26 & 24 & 35 & 49 \\
\hline LBd & 20,5 & 19 & 27 & 38 \\
\hline
\end{tabular}

* (Limite superior do intervalo de confiança de 95\%; Figuras 1, 2 e 3); ** Taxa de aplicação máxima anual.

CXd: Cambissolo Háplico Distrófico típico; CHd: Cambissolo Húmico Distrófico típico; LBd: Latossolo Bruno Distrófico típico; Lodo EAP: lodo de esgoto higienizado pelo método de estabilização alcalina prolongada.

Diante disso, considerando que a incubação é uma metodologia de execução demorada e que o uso de apenas um solo predominante da região (BRASIL, 2006; PARANÁ, 2009) poderá resultar em quantidade de aplicação de lodo EAP inadequada para os demais solos, a taxa de aplicação máxima anual deverá ser utilizada com cautela. Outro aspecto observado, para esses solos de material de origem semelhantes, é que o teor de matéria orgânica e acidez potencial podem ter maior influência sobre a quantidade máxima a ser aplicada do que a granulometria do solo, indicando atributos a serem observados em estudos de calibração com maior número de solos.

\section{Comparação entre 0 método da incubação com 0 método da saturação por bases}

A Tabela 5 apresenta uma comparação para a recomendação da taxa de aplicação de lodo EAP utilizando-se o método de incubação como referência (BRASIL, 2006 e PARANÁ, 2009).

Quando se considerou o PRNT da cal igual a 120\% e a saturação por bases (V\%) para a cultura igual a 70\%, verificou-se que as taxas de aplicação calculadas seriam respectivamente de 12,4; 26,0 e 20,5 t ha ${ }^{-1}$ ST, para os solos CXd, CHd e LBd (Tabela 5, coluna 1). Pelo limite superior do intervalo de predição (IP95\%) dos resultados obtidos pelo método de incubação, referentes a terceira e quarta colunas da Tabela 5, todos os solos com essas quantidades atingiriam entre os $\mathrm{pHs}\left(\mathrm{CaCl}_{2}\right) 6$ e 6,5, indicando que o método de saturação por bases, seguindo orientação de Andreoli, Pegorini e Fernandes (2001), apresentou-se potencialmente adequado para determinação da taxa de aplicação máxima de lodo EAP.

Por outro lado é importante ressaltar que a quantidade máxima de lodo EAP a ser aplicada estará também vinculada aos demais critérios da resolução CONAMA 375/06 (BRASIL, 2006), entre eles metais pesados, cujos valores do lodo utilizado (Tabela 2) são inferiores aos determinados na resolução SEMA 001/07 (PARANÁ, 2009) e principalmente em relação ao nitrogênio, cuja aplicação não deve exceder a quantidade a ser extraída pela cultura.

Os resultados indicam a importância da continuidade dos estudos do método de incubação do solo com lodo EAP como metodologia de referência, pois embora seja de monitoramento direto, o que lhe confere maior precisão, é de execução demorada. Assim, um trabalho comparativo com o método de saturação por bases (V\%) dos lodos EAP produzidos nas ETEs do Estado do Paraná poderá incluir um estudo do poder corretivo, tanto da cal adicionada quanto da mistura final, visando aproximar a recomendação do lodo EAP aos valores obtidos pelo método de incubação. Isso permitirá agilizar o processo de recomendação do lodo EAP para diversos solos da região de abrangência de cada ETE, com maior segurança na determinação taxa de aplicação.

Tendo em vista os dados observados neste trabalho, sugere-se cautela na seleção de apenas um solo por região para o estabelecimento da taxa de aplicação máxima anual de Lodo EAP, tendo em vista que foram identificadas importantes variações entre as respostas dos solos estudados.

\section{Conclusões}

Os três solos apresentaram elevação do pH com o aumento das doses do lodo de esgoto aplicadas.

O solo CXd apresentou o maior valor médio de $\mathrm{pH}$, tanto geral quanto em função das doses em todos os tempos, refletindo dessa forma no valor limite da taxa de aplicação máxima de lodo de esgoto higienizado pelo processo de estabilização alcalina prolongada (31 t $\mathrm{ha}^{-1}$ ST) a ser aplicada entre os três solos representativos da Região Metropolitana de Curitiba.

O método de saturação por bases (V\%) foi adequado para a recomendação da quantidade de lodo EAP a aplicar, pois indicou quantidades iguais ou ligeiramente superiores às que obtiveram $\mathrm{pH}$ entre 6 e 6,5 pelo método da incubação para os três solos, não ultrapassando o limite exigido pela legislação ( $\mathrm{pH}$ 7).

\section{Agradecimentos}

À Unidade de Serviço de Esgoto da Região Metropolitana de Curitiba (USEG) e aos profissionais da Estação de Tratamento de Esgotos Guaraituba pela cessão dos equipamentos e pelo apoio para as atividades desta pesquisa. Ao estagiário da Sanepar Caio Cesar Simão, acadêmico do curso de Engenharia Agronômica, pelo auxílio; e ao estatístico Nério Cardoso pelo apoio profissional na área. 


\section{Referências}

ANDREOLI, C.V.; PEGORINI, E.S.; FERNANDES, F. Disposição do lodo no solo. In: ANDREOLI, C.V.; SPERLING M.V.; FERNANDES F. Lodo de esgoto: tratamento e disposição final. Belo Horizonte: Universidade Federal de Minas Gerais, Departamento de Engenharia Sanitária e Ambiental; SANEPAR, 2001. 484 p. 319-397.

BARBIN, D. Componentes de variância: teoria e aplicações. Piracicaba: FEALQ, 2004.

BARCELAR, C.A. et al. Efeito residual do lodo de esgoto alcalinizado em atributos químicos e granulométricos de um Cambissolo Húmico. Scientia Agraria, Curitiba, v. 2, n. 1-2, p. 87-91, 2001.

BRASIL. Ministério do Meio Ambiente. Conselho Nacional do Meio Ambiente. Resolução CONAMA n` 375. Define critérios e procedimentos para o uso agrícola de lodos de esgoto gerados em estações de tratamento de esgoto sanitário e seus produtos derivados. Diário Oficial da República Federativa do Brasil, Brasília, n. 167, p. 141-146, 30 ago 2006.

CAVIGLIONE, J.H. et al. Cartas climáticas do Paraná. Londrina: IAPAR, 2000. CD-Rom.

CHUEIRI, W. et al. Lodo de esgoto e fertilizante mineral sobre parâmetros do solo e de plantas de trigo. Revista Brasileira de Engenharia Agrícola e Ambiental, Campina Grande, v. 11, n. 5, p. 502-508, 2007.

COMISSÃO DE QUÍMICA E FERTILIDADE DO SOLO- CQFSRS/SC. Recomendação de adubação e de calagem para os estados do Rio Grande do Sul e Santa Catarina. 2. ed. Passo Fundo: SBCS - NRS/ EMBRAPA-CNPT, 1989.

DEMETRIO, C.G.B. Modelos lineares generalizados em experimentação agronômica. Piracicaba: ESALQ. Departamento de Ciências Exatas, 2001.

DRAPER, N.R.; SMITH JR., H. Apllied regression analysis. 3. ed. New York: John Wiley, 1998.

EMPRESA BRASILEIRA DE PESQUISA AGROPECUÁRIA (EMBRAPA). Serviço Nacional de Levantamento e Conservação do Solo. Manual de métodos de análise do solo. Rio de Janeiro, 1997.

ENVIRONMENTAL PROTECTION AGENCY (EPA). Environmental regulation and technology control of pathogens and vector attraction in sewage sludge. 40 CFR. Part 503. 625/R-92/013, 1992.

FAGÉRIA, N.K. Resposta de arroz de terras altas, feijão, milho e soja à saturação por bases em solo de Cerrado. Revista Brasileira de Engenharia Agrícola e Ambiental, Campina Grande, v. 5, n. 3, p. 416-424, 2001

FASOLO, P.J. et al. Levantamento de reconhecimento dos solos - região sudeste do estado do Paraná (áreas 4,5,6). Rio de Janeiro: Embrapa Solos, 2002. (Boletim de Pesquisa de Desenvolvimento, 13)

FERNANDES, F. et al. Eficiência dos processos de desinfecção do lodo da ETE-Belém com vista a seu uso agrícola. Sanare, Curitiba, v. 5, n. 5, p. $46-58,1996$
LIMA, M.R. de. Atributos de solos e macrófitas aquáticas flutuantes: uma contribuição à sustentabilidade agrícola e ambiental na bacia do Rio Iraí (PR). Curitiba. 111f. Tese (Doutorado em Agronomia). Universidade Federal do Paraná, Curitiba, 2005.

MARQUES, R.; MOTTA, A.C.V. Análise química do solo para fins de fertilidade. In: LIMA, R.M. (Org.). Manual de diagnóstico da fertilidade e manejo dos solos agrícola. Curitiba: Universidade Federal do Paraná, Departamento de Solos e Engenharia Agrícola, 2003. p. 81-102

MATOS, A.T.; FIA, R.; AGUIRRE, C.I. Características químicas de solo adubado com doses de lodo de esgoto caleado. Engenharia na Agricultura, Viçosa, v. 13, n. 4, p. 287-299, 2005.

MELLO, F.A.F. et al. Fertilidade do solo. 2. ed. São Paulo: Nobel, 1984.

MONTGOMERY, D.C. Design and analysis of experiments. 3. ed. New York: John Wiley, 2001

OLENIK, J. etal. Análise de solo; tabela para transformação de resultados analíticos e interpretação. 3. ed. Curitiba: EMATER, 2004.

PARANÁ. Secretaria de Estado de Meio Ambiente e Recursos Hídricos. Resolução SEMA 021/09. Dispõe sobre licenciamento ambiental, estabelece condições e padrões ambientais e dá outras providências, para empreendimentos de saneamento. Diário Oficial do Estado do Paraná, Curitiba, n. 7962, p. 13-16, 2009.

RAIJ, B. van. Fertilidade do solo e adubação. Piracicaba: Ceres, Potafos, 1991.

RAIJ, B. van, et al. Recomendações de adubação e calagem para o Estado de São Paulo. Campinas: IAC, 1996.

R DEVELOPMENT CORE TEAM. R. A language and environment for statistical Computing. Vienna: R Foundation for Statistical Computing. Disponível em: < http://www.R-project.org > . Acesso em: fevereiro de 2008.

SANEPAR. Companhia de Saneamento do Paraná. Plano diretor de resíduos de sistemas de esgotamento sanitário para o Paraná. Curitiba, 2007.

SANTOS JÚNIOR, J.B. dos; LIMA, M. R. de; BICCA NETO, H. Descrição morfológica, química e física de solos em uma toposseqüência na bacia do rio Curralinho. In: EVENTO DE INICIAÇÃO CIENTÍFICA DA UFPR, 13. 2005, Curitiba. Livro de resumos... Curitiba: Universidade Federal do Paraná, 2005. p. 69.

SILVA, F.C. et al. Efeito de lodo de esgoto na fertilidade de um Argissolo Vermelho-Amarelo cultivado com cana-de-açúcar. Pesquisa Agropecuária Brasileira, Brasília, v. 36, n. 5, p. 831-840, 2001.

THOMAZ-SOCCOL, V.; PAULINO, R.C.; CASTRO, E. Aspectos sanitários do uso agrícola do lodo de esgoto: helmintos e protozoários. In: Reciclagem agrícola de lodos - transformando problemas em soluções. Curitiba: Sanepar/ABES, 1999. p. 156-179. 